\title{
Establishing a model of primary bovine hepatocytes with responsive growth hormone receptor expression
}

\author{
S. Witte, ${ }^{1}$ Y. Brockelmann, ${ }^{1}$ J.-D. Haeger, ${ }^{2}$ and M. Schmicke ${ }^{1 *} \dagger$ \\ ${ }^{1}$ Clinic for Cattle, Endocrinology Laboratory, University of Veterinary Medicine Hannover, Bischofsholer Damm 15, 30173, Germany \\ ${ }^{2}$ Institute for Anatomy, University of Veterinary Medicine Hannover, Bischofsholer Damm 15, 30173, Germany
}

\section{ABSTRACT}

The liver becomes resistant to growth hormone before parturition in dairy cows (uncoupling of the somatotropic axis). However, the mechanism of growth hormone insensitivity has not been fully described. The aim of the present study was to improve a previous model of adult bovine hepatocytes in a sandwich culture system to ensure growth hormone receptor (GHR) expression. First, we modified the protocol for hepatocyte retrieval and tested the effect of short (18 $\mathrm{min})$ and long (up to $30 \mathrm{~min}$ ) warm ischemia on hepatocyte viability. Second, we used medium additives that affect GHR expression in vivo-insulin (INS), dexamethasone (DEX), both (INS+DEX), or no hormone additives (CTRL) - to ensure the functionality of hepatocytes, as measured by lactate dehydrogenase activity and urea concentration in the medium. We also used reverse transcriptase PCR of hepatocytes to evaluate expression of albumin $(A L B)$, hepatocyte nuclear factor $4 \alpha$

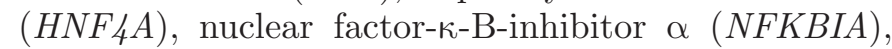
cytosolic phosphoenolpyruvate carboxykinase (PCK1), and vimentin (VIM) mRNA. Moreover, we analyzed the expression of GHRtot (GHR), GHR1A, insulin-like growth factor-1 (IGF1), and IGF binding protein-2 (IGFBP2) in response to exposure to media with the different compositions. Modification of the protocol (changes in rinsing and perfusion times, buffer composition, and the volume and standardization of collagenase) led to increased cell counts and cell viability. Short warm ischemia with the modified protocol significantly increased cell count $\left(4.7 \times 10^{7} \pm 1.9 \times 10^{7}\right.$ vs. $3.5 \times 10^{6} \pm 1.5 \times 10^{6}$ vital cells/g of liver) and viability $(79.1 \pm 8.4$ vs. $37.1 \pm 8.9 \%)$. Therefore, we gathered hepatocytes from the liver after short warm ischemia

Received October 18, 2018

Accepted April 3, 2019.

*Corresponding author: marion.schmicke@Landw.uni-halle.de

$\dagger$ Martin-Luther Universität Halle-Wittenberg, 06020 Halle, Germany. with the modified protocol. For these hepatocytes, lactate dehydrogenase activity was lower in media with INS and with DEX than in media with INS+DEX or CTRL; urea concentrations were highest at $\mathrm{d} 4$ for INS+DEX. As well, HNF $4 A$ and $A L B$ were more highly expressed in hepatocytes cultured with INS and INS+DEX than in those cultured with DEX or CTRL, and the substitution of DEX suppressed VIM and NFK$B I A$ expression but increased $P C K 1$ expression. The expression of $G H R, G H R 1 A$, and IGF1 was suppressed by dexamethasone (DEX and INS+DEX), whereas INS distinctly increased GHR, GHR1A, and IGF1 mRNA expression. Hepatocytes in a sandwich culture showed influenceable GHR expression; this study provides a model that can be used in studies examining factors that influence the expression and signal transduction of GHR in dairy cows.

Key words: growth hormone, insulin-like growth factor, hepatocytes, sandwich culture

\section{INTRODUCTION}

The liver is one of the most important organs in the body and serves a variety of major functions, including metabolic and immunological ones. It plays a key role in carbohydrate, protein, and fat metabolism and has been considered in many studies in high-yield dairy cows. To examine the function of the liver in detail, well-described in vitro models are necessary. The present study focuses on establishing a model to examine hepatic growth hormone receptor (GHR) regulation, because in high-yield dairy cows, the liver becomes resistant to growth hormone before parturition (Kobayashi et al., 1999), called the uncoupling of the somatotropic axis (Lucy et al., 2001). However, the mechanism behind growth hormone resistance has not yet been fully elucidated. The expression and signal transduction of GHR can be regulated at several levels, for example by modifying receptor expression, surface availability and GHR signaling, which involves at least 3 major pathways: signal transducer and activator of transcrip- 
tion proteins (STAT); mitogen-activated protein kinase (MAPK); and phosphoinositide 3-kinase (PI3)/Akt. Various immune factors and hormones such as insulin, thyroid hormones, cortisol, and sex hormones can modulate GHR through some of these mechanisms (FloresMorales et al., 2006). Dexamethasone downregulates GHR expression and decreases peripheral IGF-1 in cows after $5 \mathrm{~d}$ without affecting IGF binding proteins (IGFBP; Bennett et al., 1996; Maciel et al., 2001). In dairy cows, low insulin concentrations are thought to be responsible for the decreased expression of GHR, and the infusion of cows with supraphysiological concentrations of insulin increases GHR expression in the liver (Butler et al., 2003). Other studies indicate that insulin might be only one of the factors that affect peripartal GHR expression (Leung et al., 2003; Winkelman et al., 2008). Cows with very different IGF-1 levels but comparable GHR expression also show comparable insulin levels (Piechotta et al., 2013, 2014). Therefore, not only is GHR expression likely impaired, but also GHR signal transduction. Winkelman et al. (2008) found increased SOCS2 expression around calving, but which factor induces SOCS2 expression remains unclear. Therefore, we established a cell culture model for detailed study (Ehrhardt and Schmicke, 2016). Ehrhardt and Schmicke (2016) had 2 major limitations when using a model of primary bovine hepatocytes from abattoirderived liver. First, the gathered cell count was low, and second, GHR expression was impaired. The aim of the present study was to evaluate the effect of factors during hepatocyte gathering and the effect of insulin and dexamethasone on cell count and GHR expression in adult primary bovine hepatocytes to modify isolation and culture conditions to ensure GHR expression.

\section{MATERIALS AND METHODS}

\section{Experimental Design}

To ensure GHR expression in a primary hepatocyte cell culture, we hypothesized that modifying the 2-step collagenase perfusion and culturing conditions led to basal and reactive GHR expression. Therefore, we designed 2 experiments. In experiment 1, we modified a previously published protocol for gathering primary bovine hepatocytes from abattoir-derived liver and tested whether cell count and cell viability (ratio of live to dead cells) could be improved compared with the original protocol. We also evaluated the influence of the duration of warm ischemia on cell yield and viability in primary bovine hepatocytes depending on the protocol (original versus modified). In experiment 2, we cultured the cells in a sandwich culture and tested the influence of insulin and dexamethasone on GHR expression.

\section{Experiment 1: Isolation of Primary Hepatocytes and Influence of Warm Ischemia}

Based on the previously published protocol for isolation of bovine hepatocytes (Ehrhardt and Schmicke, 2016), we established the following modified protocol that differed primarily in terms of buffer composition, increased buffer volume for rinsing, and temperature of rewarming $\left(37^{\circ} \mathrm{C}\right)$ and stop solution $\left(4^{\circ} \mathrm{C}\right)$. Unless otherwise stated, all chemicals were purchased from Sigma-Aldrich (St. Louis, MO). In brief, the following steps were modified. The liver was rinsed via vessels at the surface of the 30- to 90-g part of the lobus caudatus with $250 \mathrm{~mL}$ of EGTA buffer $\left(4^{\circ} \mathrm{C}\right)$ and then with $200 \mathrm{~mL}$ of EGTA-free buffer $\left(4^{\circ} \mathrm{C}\right.$, Table 1$)$. The liver was then transported to the cell culture laboratory in a glass jar with $250 \mathrm{~mL}$ of EGTA-free buffer on ice. The time between the rinsing of the liver part and the start of the perfusion was 30 to $90 \mathrm{~min}$. In the cell culture laboratory, the liver was rewarmed with $150 \mathrm{~mL}$ of EGTA-free buffer $\left(37^{\circ} \mathrm{C}\right)$. Then, a 2-step collagenase perfusion was performed using EGTA buffer $\left(39^{\circ} \mathrm{C}\right)$ for $5 \mathrm{~min}, \mathrm{CaCl}_{2}$ buffer $\left(39^{\circ} \mathrm{C}\right)$ for $5 \mathrm{~min}$, and $1 \mathrm{mg}$ of collagenase $\mathrm{P}$ per gram of liver in $\mathrm{CaCl}_{2}$ buffer for 5 to 7 min. Afterward, the liver was placed on ice again, and cells were flushed out with stop solution $\left(4^{\circ} \mathrm{C}\right.$, Williams' Medium E with 20\% FBS; PAN-Biotech, Aidenbach, Germany). The cells were then centrifuged $(60 \times g$, 3 min, $4^{\circ} \mathrm{C}$ ), and cell count and cell viability were determined as described by Ehrhardt and Schmicke (2016). Vital hepatocytes were purified using $75 \%$ PBS and $25 \%$ Easycoll (density $1.124 \mathrm{~g} / \mathrm{mL}$; Merck, Darmstadt, Germany) and centrifuged for $8 \mathrm{~min}$ at $1,000 \times g$ and $4^{\circ} \mathrm{C}$. After purification, we measured cell count and cell viability again.

To validate the influence of the liver material on cell viability and cell count, we compared livers from 2 different sources. First, we used livers with a long warm ischemia time (LWI; $\mathrm{n}=12,28-30 \mathrm{~min}$ from slaughtering to cold buffer) from a commercial slaughterhouse, comparable to those used in Ehrhardt and Schmicke (2016). Second, livers from primiparous cows $30 \mathrm{~d}$ after calving were available from the "Chron mast project" (experiment approved by the Lower Saxony Federal State Office for Consumer Protection and Food Safety under the reference number 33.12-42502-04-15/2024; $\mathrm{n}=12,18 \mathrm{~min}$ from slaughtering to cold buffer, short warm ischemia time, SWI). These 24 livers from the 2 sources were perfused using the original protocol (Eh- 
Table 1. Composition of buffers used in the 2-step collagenase perfusion of the caudate liver lobe obtained after death from an adult cow: modified protocol (present study) versus the original protocol (Ehrhardt and Schmicke, 2016)

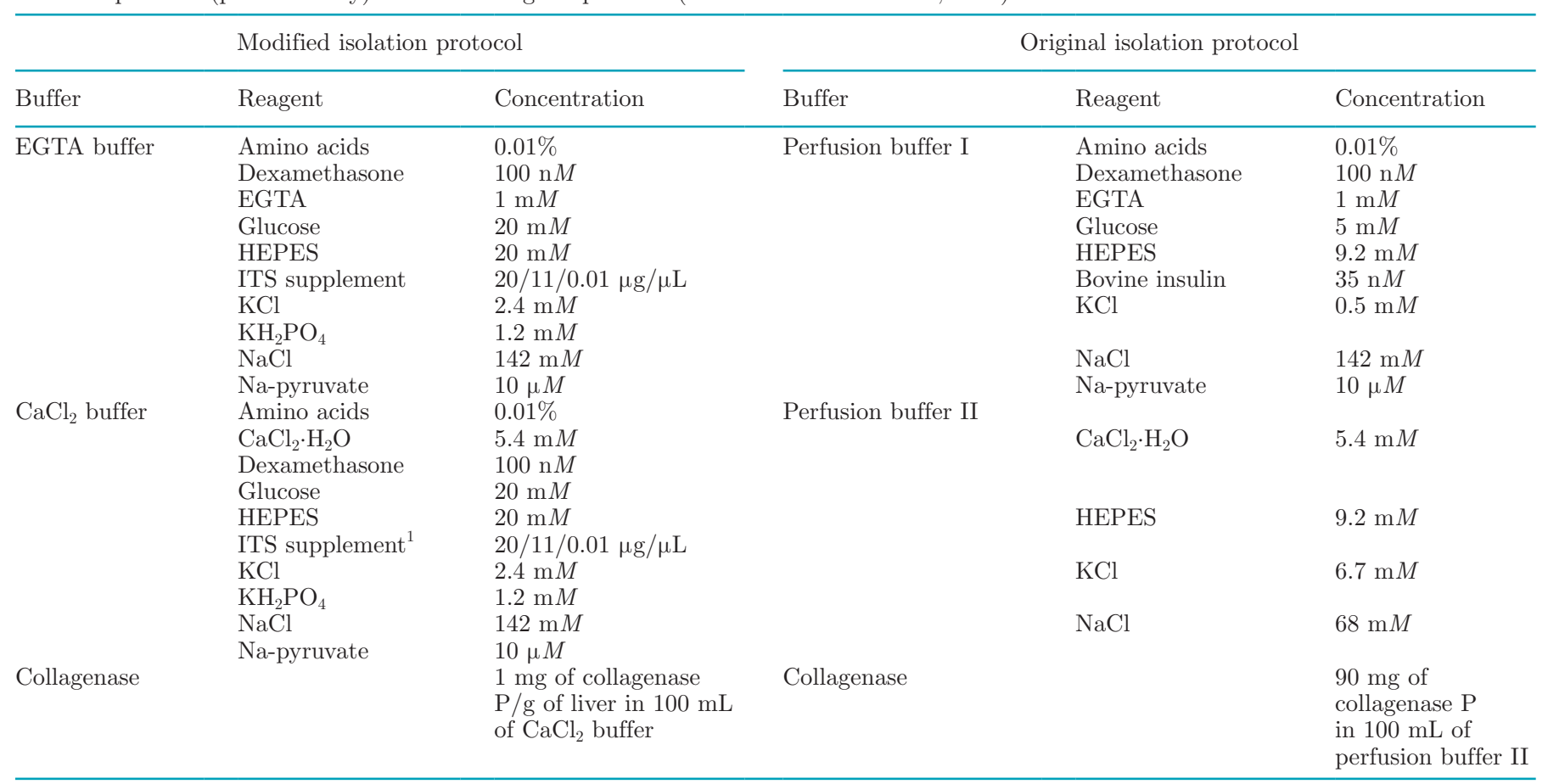

${ }^{1}$ ITS $=$ insulin-transferrin-selenium.

rhardt and Schmicke, 2016; $\mathrm{n}=6$ SWI, $\mathrm{n}=6 \mathrm{LWI})$ or the modified protocol $(\mathrm{n}=6 \mathrm{SWI}, \mathrm{n}=6 \mathrm{LWI})$.

\section{Experiment 2: Sandwich Culture of Primary Hepatocytes and Effect of Insulin and Dexamethasone on GHR Expression}

After hepatocytes were isolated using the modified protocol, they were seeded on collagen-coated 12-well plates $\left(1.37 \times 10^{5}\right.$ vital cells $\left./ \mathrm{cm}^{2}\right)$ in Williams' Medium E with $10 \%$ fetal bovine serum. After $3 \mathrm{~h}$, the cells were washed with $10 \%$ PBS, and a second collagen layer was added to prepare a sandwich culture. Hormone-free Williams' Medium E was replaced after the second collagen layer was solidified. Cells were cultured in a humidified atmosphere at $37^{\circ} \mathrm{C}$ and $5 \% \mathrm{CO}_{2}$. The medium was changed $18 \mathrm{~h}$ after separation to a hormone-defined medium that was equivalent to Williams' Medium E with dexamethasone (DEX), insulin (INS), both (DEX+INS), or neither (CTRL).

The bovine hepatocytes were cultured in standard medium for liver cells, which is hormone-defined Williams' Medium E containing penicillin/streptomycin (100 U/mL, $0.1 \mathrm{mg} / \mathrm{mL})$, gentamicin $(50 \mu \mathrm{g} / \mathrm{mL})$, amphotericin B $(2.5 \mu \mathrm{g} / \mathrm{mL})$, and L-glutamine (4 $\mathrm{m} M$ ). In Ehrhardt and Schmicke (2016), INS (100 nM) and DEX (100 nM) were added to the medium. Both hormones influence GHR expression in vitro and in vivo. Therefore, we isolated bovine hepatocytes with a SWI and the modified protocol with either INS, DEX, INS+DEX or CTRL. In the cell culture medium, we measured lactate dehydrogenase (LDH) activity and urea as parameters indicating liver cell viability, and in cell samples, we determined genes of interest (Table 2).

\section{Laboratory Analyses}

Live/Dead Stain. To evaluate the viability and morphology of the primary bovine hepatocytes at $d$ 1 and 4 after perfusion, the cells were stained using a LIVE/DEAD Viability/Cytotoxicity Kit (ThermoFisher Scientific, Waltham, MA) and following the manufacturers' instructions (https://www.thermofisher .com/order/catalog/product/L3224). We observed the results using an inverse fluorescence microscope (Axiovert 200M; Zeiss, Oberkochen, Germany). From 6 wells of INS, DEX, INS + DEX, and without any hormonal additive (CTRL), micrographs were taken and cells were counted and the percentage of dead/live cells was calculated in one visual field.

Urea and Lactate Dehydrogenase Measurement in Cell Culture Medium. The urea concentration was measured using the Urea Assay Kit ab83362 (Abcam, Cambridge, UK), and LDH activity using a 
Lactate Dehydrogenase Activity Assay Kit (SigmaAldrich). Both assays were performed according to the manufacturers' instructions (https://www.sigmaaldrich .com/catalog/product/sigma/mak066?lang=de\&region $=\mathrm{DE})$. The intra-assay coefficients of variation were $6.1 \%$ for urea and $5.2 \%$ for $\mathrm{LDH}$.

mRNA Isolation and Quantitative Reverse Transcription $P C R$. We determined the expression of HNF4A, NFKBIA, ALB, PCK1, VIM, GHR, GHR1A, IGF1, and IGFBP2 mRNA in the cell samples after 6 and $72 \mathrm{~h}$ of incubation using quantitative reverse transcriptase PCR. Therefore, total RNA was extracted using Trizol Reagent (Sigma-Aldrich) according to the original protocol (Ehrhardt and Schmicke, 2016). To assess the quality and quantity of the extracted RNA, we determined relative integrity using an RNA 6000 Nano Assay Kit and an Agilent 2100 Bioanalyzer (Agilent Technologies, Böblingen, Germany). To transcribe RNA into cDNA, we used a CFX96 C1000 Touch thermocycler (Real-Time PCR detection system, BioRad, Munich, Germany) as previously described (Piechotta et al., 2013). For the genes of interest, the $\mathrm{PCR}$ reaction mix contained $1.25 \mathrm{ng} / \mu \mathrm{L}$ cDNA, $4 \mu \mathrm{L}$ of HOT FIREPol EvaGreen qPCR Supermix (5×; Solis BioDyne, Tartu, Estonia), and $0.2 \mu M$ each primer (Eurofins MWG Operon, Ebersberg, Germany). The primers were either previously described or constructed based on information in a public database (https:// www.ncbi.nlm.nih.gov/tools/primer-blast/index.cgi). The primer sequences and accession numbers are shown in Table 2. The PCR cycler was programmed as fol- lows: activation of the DNA polymerase at $95^{\circ} \mathrm{C}$ for 720 $\mathrm{s}$, followed by 40 cycles of RNA denaturation at $95^{\circ} \mathrm{C}$ for $15 \mathrm{~s}$, annealing at $60^{\circ} \mathrm{C}$ for $30 \mathrm{~s}$, and elongation at $72^{\circ} \mathrm{C}$ for $30 \mathrm{~s}$. We used HOT FIREPol EvaGreen to visualize the fragments. A melting curve was generated to verify PCR fragments. The PCR was initiated at $55^{\circ} \mathrm{C}$, increasing to a final temperature of $95^{\circ} \mathrm{C}$, with a temperature increase of $0.5^{\circ} \mathrm{C}$ every $5 \mathrm{~s}$. Finally, we determined the relative abundance of genes of interest relative to a calibrator (cells were collected immediately after the purification step with Easycoll and directly frozen at $-80^{\circ} \mathrm{C}$ until analyses) and calculated it using the $\Delta \Delta \mathrm{Ct}$ method with respect to the different efficiencies of the primers (Pfaffl, 2004). We used GAPDH and peptidylprolyl-isomerase A (PPIA) as reference genes. The mRNA expression of both reference genes was tested for effects of time or treatment and it was not affected and therefore suitable as reference genes.

\section{Statistical Analyses}

The statistical analyses were performed using GraphPad Prism 7 (GraphPad Software, La Jolla, CA). First, we tested data for normal distribution using the Shapiro-Wilk test: all data were normally distributed. In experiment 1 , to test the main effect of the isolation protocol (original versus modified), warm ischemia, and the interaction between isolation protocol and warm ischemia, we performed a 2-way ANOVA using a post hoc Sidak test. For experiment 2 (urea concentration and $\mathrm{LDH}$ activity in the media), we performed a 2 -way

Table 2. Genes of interest used in the quantitative reverse transcription PCR

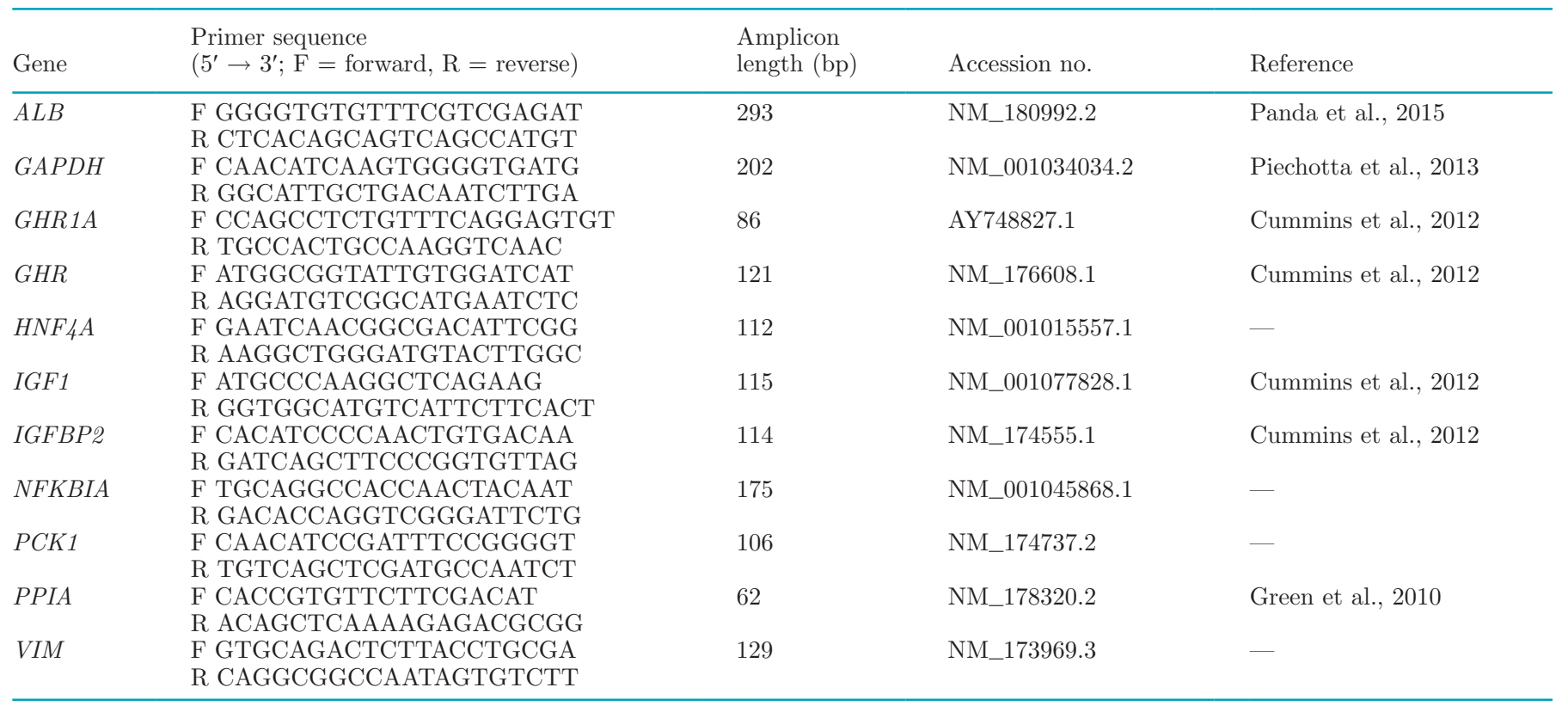


Table 3. Cell count and cell viability of primary bovine hepatocytes obtained from adult cows ${ }^{1}$

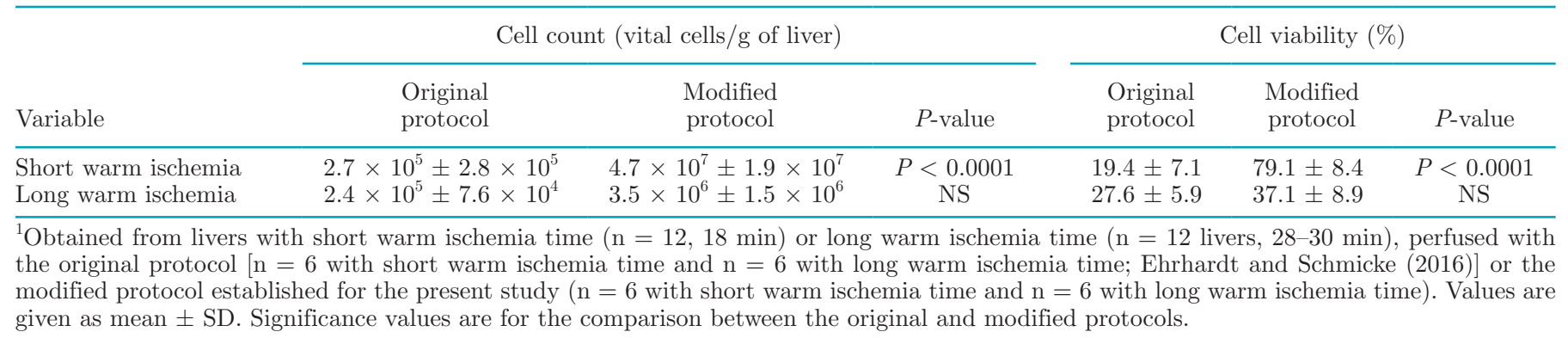

ANOVA with the main effects of time, treatment (INS, DEX, INS+DEX, CTRL) and their interaction using a post hoc Tukey test. Overall, mRNA expression was also normally distributed; therefore, we performed a 2-way ANOVA with the main effects of day, treatment (INS, DEX, INS+DEX, CTRL) and their interaction. We used a Sidak test or Tukey test as a post hoc test, and a $P$-value of $<0.05$ was considered significant.

\section{RESULTS}

\section{Experiment 1}

The modified perfusion protocol ensured a higher cell count than that of the original protocol (Ehrhardt and Schmicke, 2016) when using livers with an SWI $(P<$ 0.0001; Table 3). Both cell count and cell viability were higher in livers with an SWI than in those with an LWI when using the modified protocol $(P<0.001$; Table 3$)$.

\section{Experiment 2}

Based on the results from experiment 1, we performed experiment 2 using hepatocytes from livers with SWI isolated using the modified protocol.

Morphology. Figure 1 (a to d) shows primary bovine hepatocytes cultured in a sandwich culture at d 1 (24 h) with INS, DEX, INS+DEX, and CTRL. Morphologically, we detected no obvious difference in bovine hepatocytes with the different hormone substitutes in Williams' Medium E. Under all culture conditions, we detected single dead cells, indicated by a red nucleus and an unstained cytoplasm. The morphology of the hepatocytes was round. Cells attached as isolated, singular cells were from colonies consisting of 2 to 4 cells. When hepatocytes were cultured with DEX and INS+DEX, we observed bright elucidations between 2 hepatocytes, indicative of canaliculi formation (Figure 1, white arrows). At d 4 [Figure 1 (e to h)], the cellular morphology changed to cuboidal and polygonal, and hepatocytes formed cords reminiscent of hepatic trabeculae. We also detected bile canaliculi (bright elucidations between hepatocytes; Figure 1, white arrows). In culture with INS (Figure 1e), the hepatocytes were somewhat flattened, whereas hepatocytes showed cytoplasmic protrusions (white stars) when cultured with DEX (Figure 1f), INS+DEX (Figure $1 \mathrm{~g}$ ), and even CTRL (Figure 1h). When hepatocytes were cultured with INS+DEX, the polygonal cell shape was dominant, with fewer obvious dead cells than in cultivation without DEX. With INS and CRTL, the red cells increased, but we did not assess those morphological changes quantitatively. Under all cultivation conditions, at d 4 we detected hepatocytes with 2 nuclei [Figure 1 (e to h), blue arrow]. The percentage of dead cells was higher in INS at d 4 than in DEX, INS+DEX, or CTRL (Table 4).

Urea Concentration and $L D H$ Activity. We found that LDH activity increased at d 2 in all groups $(P<0.0001)$ and then decreased continuously, with the lowest LDH leakage detected at $\mathrm{d} 4$. The LDH activity at d 2 was lower in media with INS and with DEX than in media with INS+DEX or CTRL $(P<0.05$; Figure 2). Urea concentrations were low at $\mathrm{d} 1$ and then increased continuously in media with DEX and INS+DEX $(P<0.0001)$. We found the highest urea production at $\mathrm{d} 4$ for INS+DEX followed by DEX. In contrast, in media with INS and CTRL, we detected no comparable increase in urea (Figure 2).

mRNA Expression. We found that HNF4A and $A L B$ were more highly expressed in hepatocytes cultured with INS and INS+DEX than in those cultured with DEX or CTRL. The substitution of DEX suppressed VIM and NFKBIA expression $(P<0.0001)$, but increased $P C K 1$ expression $(P<0.0001)$. The substitution of INS suppressed $P C K 1$ expression, but increased HNF $4 A$ and $A L B$ expression $(P<0.0001$; Figure 3).

The expression of GHR, GHR1A, and IGF1 was suppressed by dexamethasone $(P<0.0001$; DEX and INS+DEX), whereas INS distinctly increased $G H R$, GHR1A, and IGF1 mRNA expression $(P<0.0001)$. The cultivation of primary bovine hepatocytes without any hormone substitutes (CTRL) also led to basic 
a) INS
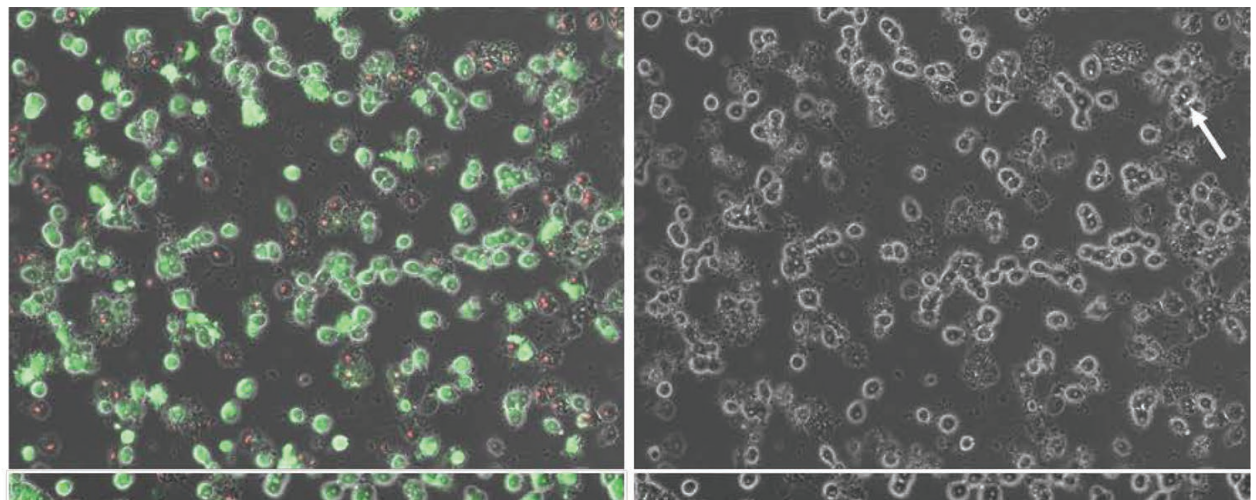

b)

DEX
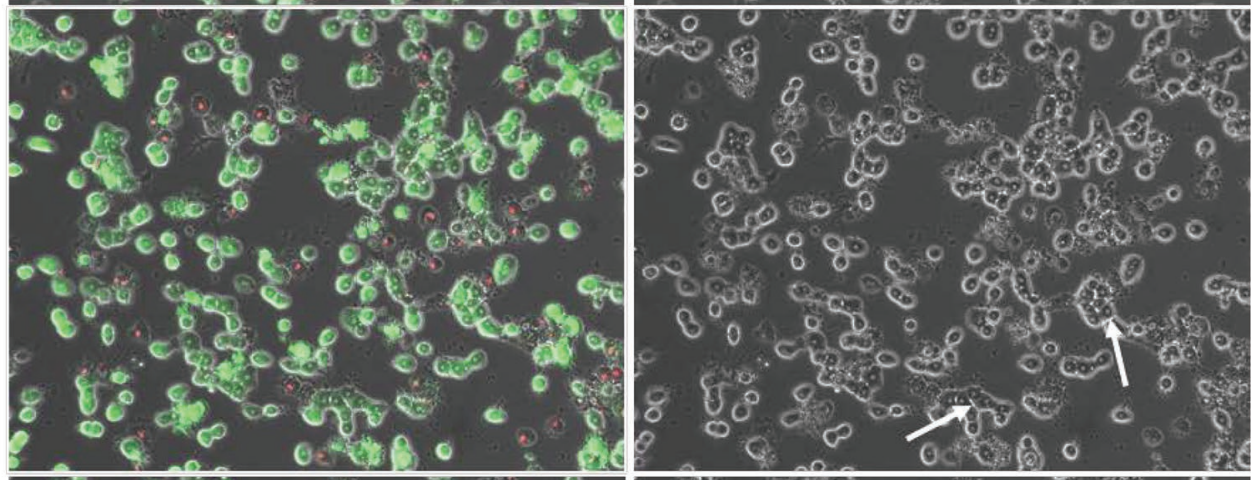

c)

INS+
DEX
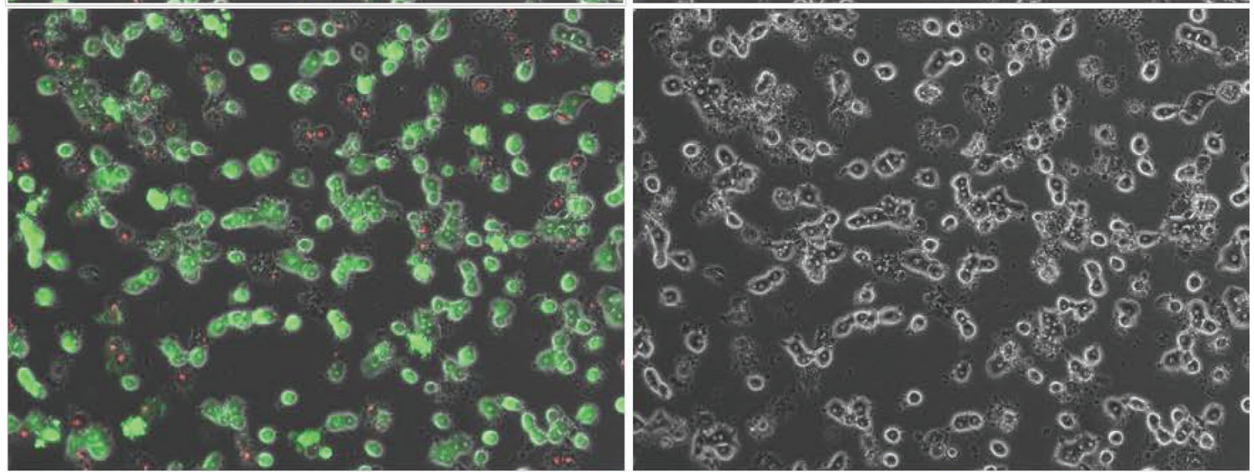

d)

CTRL
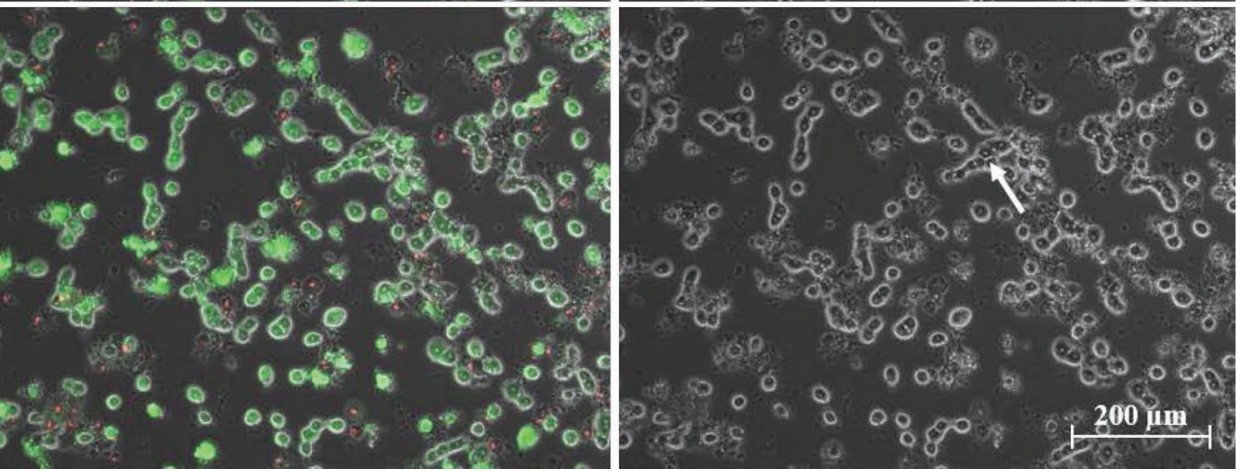

Figure 1. Live/dead staining of primary bovine hepatocytes at (panels a-d) d 1 (24 h) or (panels e-h) d 4 (96 h) after collagenase perfusion in a sandwich culture system between 2 layers of collagen in Williams' Medium E supplemented with $100 \mathrm{n} M$ insulin (INS), $100 \mathrm{n} M$ dexamethasone (DEX), both (INS+DEX), or no hormone substitute (CTRL). Vital cells have a green cytoplasm (intracellular esterase activity, intact membrane), whereas dead cells appear with an unstained cytoplasm but a red-stained nucleus (ethidium-homodimer 1 binding to nucleic acids because of no intact membrane). Micrographs were taken with a phase-contrast microscope (Axiovert 200M with fluorescence; Zeiss, Oberkochen, Germany) and AxioVision software (https://www.zeiss.com/microscopy/int/products/microscope-software/axiovision.html). White arrows indicate a brightening between 2 hepatocytes indicative of canaliculi; blue arrows indicate hepatocytes with 2 nuclei; white stars indicate hepatocytes with cytoplasmic extensions (in one example, cells are additionally highlighted in violet); orange indicates cells in hepatocytic cords. Images on the left side are merged (phase contrast and fluorescence); images on the right side are phase-contrast only. 


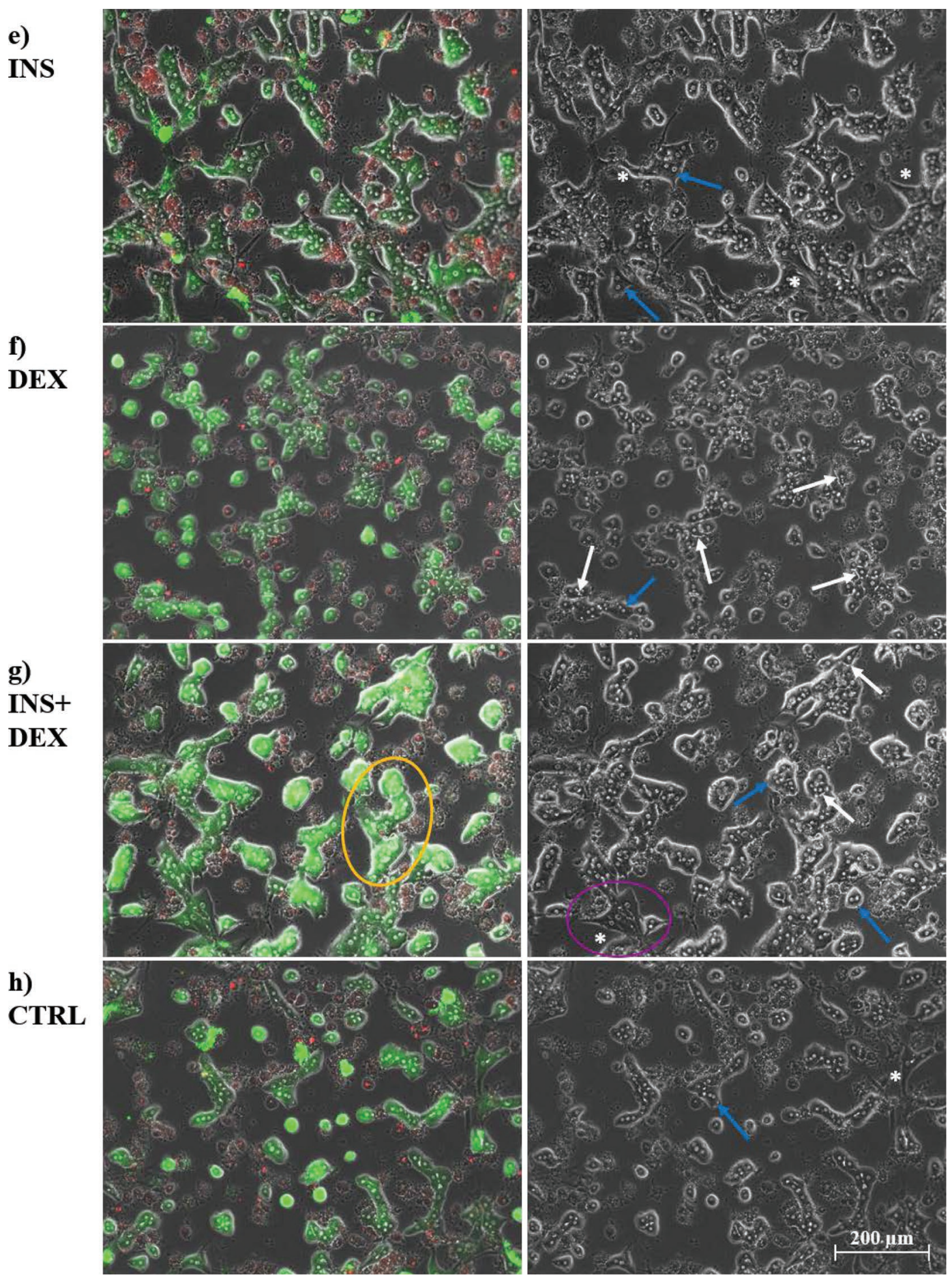

Figure 1 (Continued). Live/dead staining of primary bovine hepatocytes at (panels a-d) d $1(24 \mathrm{~h})$ or (panels e-h) d 4 (96 h) after collagenase perfusion in a sandwich culture system between 2 layers of collagen in Williams' Medium E supplemented with $100 \mathrm{n} M$ insulin (INS), $100 \mathrm{n} M$ dexamethasone (DEX), both (INS+DEX), or no hormone substitute (CTRL). Vital cells have a green cytoplasm (intracellular esterase activity, intact membrane), whereas dead cells appear with an unstained cytoplasm but a red-stained nucleus (ethidium-homodimer 1 binding to nucleic acids because of no intact membrane). Micrographs were taken with a phase-contrast microscope (Axiovert 200M with fluorescence; Zeiss, Oberkochen, Germany) and AxioVision software (https://www.zeiss.com/microscopy/int/products/microscope-software/axiovision.html). White arrows indicate a brightening between 2 hepatocytes indicative of canaliculi; blue arrows indicate hepatocytes with 2 nuclei; white stars indicate hepatocytes with cytoplasmic extensions (in one example, cells are additionally highlighted in violet); orange indicates cells in hepatocytic cords. Images on the left side are merged (phase contrast and fluorescence); images on the right side are phase-contrast only. 
Table 4 . Dead/live cells at $\mathrm{d} 2$ and 4 in sandwich culture $(\text { mean } \pm \mathrm{SD})^{1}$

\begin{tabular}{|c|c|c|c|c|}
\hline \multirow[b]{2}{*}{ Timepoint } & \multicolumn{4}{|c|}{ Dead/live cells (\%) } \\
\hline & INS & DEX & INS+DEX & CTRL \\
\hline Day 1 & $40.6 \pm 10.0^{\mathrm{a}}$ & $31.5 \pm 10.0^{\mathrm{a}}$ & $30.6 \pm 3.6^{\mathrm{a}}$ & $40.0 \pm 13.6^{\mathrm{a}}$ \\
\hline Day 4 & $67.0 \pm 20.0^{\mathrm{a}}$ & $34.2 \pm 11.7^{\mathrm{b}}$ & $37.0 \pm 15.7^{\mathrm{b}}$ & $47.4 \pm 22.3^{\mathrm{b}}$ \\
\hline
\end{tabular}

GHR and GHR1A mRNA expression, whereas expression was completely inhibited by DEX. The mRNA expression of IGFBP2 increased with DEX but decreased completely with INS (Figure 3).

\section{DISCUSSION}

We previously published a protocol to gather hepatocytes from abattoir-derived liver, but we could not show any basal GHR expression (Ehrhardt and Schmicke, 2016). The aim of the present study was to establish an in vitro model for use in future studies to examine factors in adult bovine hepatocytes that affect the expression and signal transduction of GHR. With our original protocol, cell yield was relatively low $\left(5.0 \times 10^{4}\right.$ cells $/ g$ of liver $)$ compared with, for example, hepatocytes gathered from fresh buffalo liver $(5.3 \pm 0.7$ $\times 10^{7}$ cells $/ g$ of liver (Panda et al., 2015). Optimization of the protocol included 3 primary aspects: warm ischemia time, perfusion protocol, and substitution of insulin and dexamethasone in the culturing medium. The latter hormones are routinely added to primary hepatocyte media, but it is known from in vivo studies that insulin and dexamethasone clearly affect GHR expression (Godoy et al., 2013).

Warm ischemia time is a well-known critical parameter for the isolation of vital hepatocytes (Ikeda et al., 1992; Fisher et al., 1997; Hughes et al., 2006). According to the National Cancer Institute of the National Institutes of Health, warm ischemia time is defined "as the time a tissue, organ, or body part remains at body temperature after its blood supply has been reduced or cut off but before it is cooled or reconnected to a blood supply" (https://www.cancer.gov/publications/ dictionaries/cancer-terms/def/warm-ischemia-time). With the cutoff of the blood supply, particularly at body temperature, cells are particularly vulnerable to damage due to hypoxia (Rauen and Groot, 2002). In particular, the warm ischemia time decreases cell viability (Caldwell-Kenkel et al., 1989, 1991; Ikeda et al., 1992). In the present study, we also demonstrated the negative effect of an LWI time on primary bovine hepatocyte viability. We further verified the findings of Ehrhardt and Schmicke (2016), that gathering cells from abattoir-derived liver is possible, but that cell count and cell viability were higher in liver with a short rather than a long warm ischemia time. Therefore, for isolation of primary bovine hepatocytes liver with a short warm ischemia time should be used, as previously indicated by Panda et al. (2015).

Buffer composition, rewarming of the liver and the 2-step collagenase perfusion are other critical steps in gathering large numbers of vital primary hepatocytes. According to Johnson et al. (1996), the duration of collagenase digestion is important, one reason being that cell surface receptors can be destroyed by protease activity. In contrast to Ehrhardt and Schmicke (2016), who used $90 \mathrm{mg}$ of collagenase $\mathrm{P}$ irrespective of liver weight, we used a concentration of $1 \mathrm{mg}$ of collagenase per gram of liver tissue in the present study. With standardized collagenase digestion, which was previously successful for gathering human hepatocytes, the number of vital cells was improved (Lee et al., 2013). Moreover, we initiated some changes in the buffer composition and temperature. The increase in cold buffer volume used for rinsing the liver directly after withdrawal from the warm animal might also be important, as also noted for cows (Forsell et al., 1985) and horses (Bakala et al., 2003). The rewarming of the liver is necessary for the collagenase perfusion that requires body temperature $\left(37-39^{\circ} \mathrm{C}\right)$ for optimal enzyme activity. In contrast to Ehrhardt and Schmicke (2016), in which rewarming occurred at $21^{\circ} \mathrm{C}$, in the present study, the buffer was at $37^{\circ} \mathrm{C}$ and the duration of the perfusion steps was reduced. Toyokuni (1999) and Bhogal et al. (2010) note that during reperfusion, the production of reactive oxygen species leads to oxidative stress, a disturbance of the redox-homeostasis, resulting in damage to intracellular components (Zuo et al., 2015) and lipid oxidation that damages cell membranes (Halliwell 2006). In further studies, the addition of antioxidants such as ascorbic acid or tocopherol should be considered. A limitation of the present study was that we did not perform each modification step separately; we were unable to evaluate which modification step was most important. 

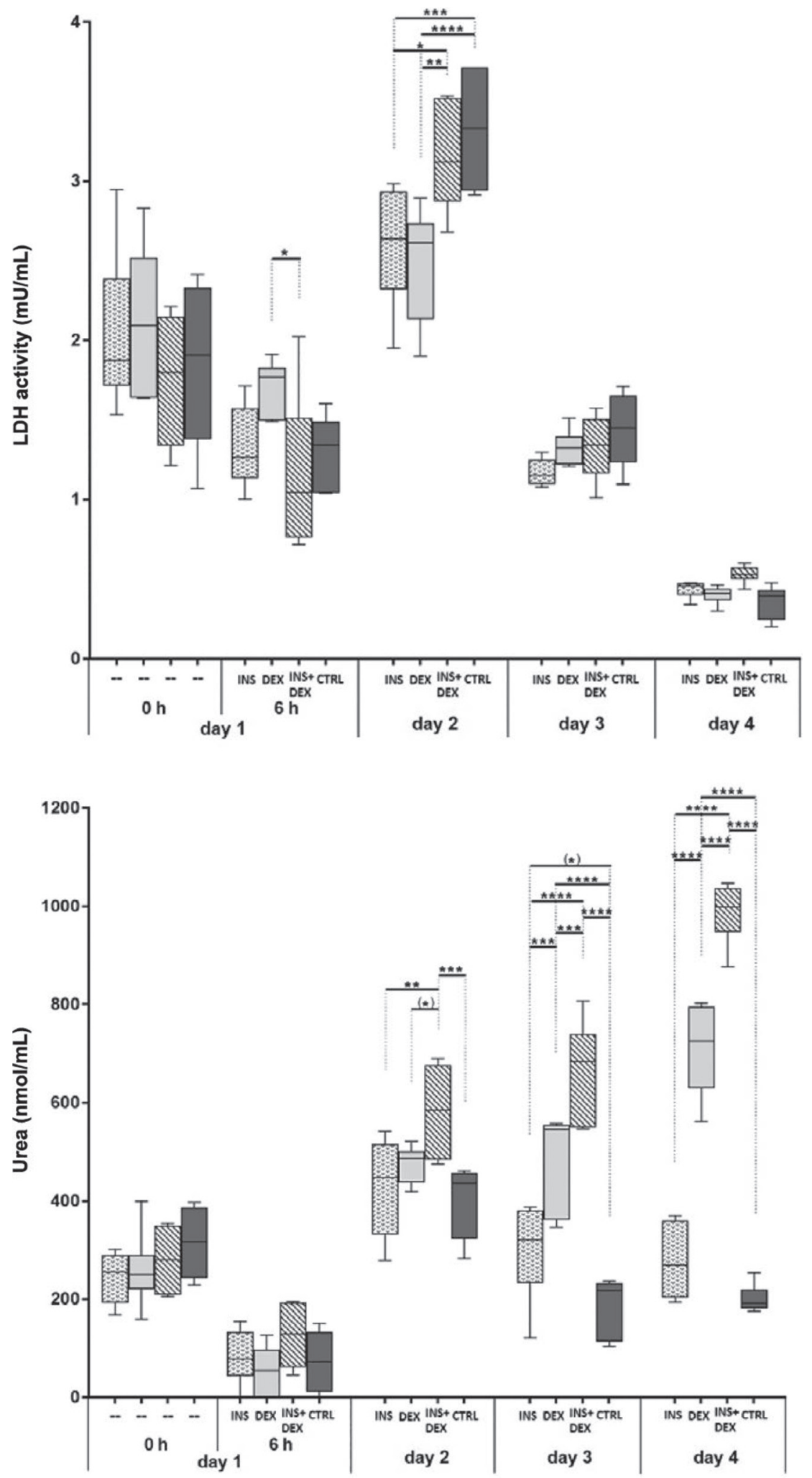

Figure 2. Lactate dehydrogenase $(\mathrm{LDH})$ activity $(\mathrm{mU} / \mathrm{mL})$ and urea concentrations $(\mathrm{nmol} / \mathrm{mL})$ measured in Williams' Medium E from adult primary bovine hepatocytes from d 1 to 4 after collecting the cells by using a collagenase perfusion in a sandwich culture system between 2 layers of rat tail collagen. CTRL $=$ no hormone substitute; DEX $=$ dexamethasone; INS $=$ insulin; INS + DEX $=$ insulin and dexamethasone. Values are given as medians with 25 and $95 \%$ quartiles. Error bars indicate minimum to maximum. Asterisks indicate significant differences at $\left({ }^{*}\right) P<0.1,{ }^{*} P<0.05,{ }^{* *} P<0.01,{ }^{* * *} P<0.001,{ }^{* * * *} P<0.0001$. 
With liver obtained after SWI and gathering hepatocytes using the optimized protocol, in experiment 2 we tested in the influences of DEX, INS, both (INS+DEX), or no hormone additive (CTRL) on adult primary bovine hepatocytes. We detected differences in the morphology of cells, which was assessed using phase-contrast microscopy and live/dead fluorescence staining. In all cultivation conditions, the hepatocytes developed an in-vivo-like polygonal cell shape, and the hepatocytes clustered into cords reminiscent of hepatic trabeculae, as previously described for rats (Tuschl und Mueller, 2006; Hewitt et al., 2007; Tchaparian et al., 2011). The collagen matrix below and above the hepatocytes in the sandwich culture promotes the formation of cell-to-cell contacts and supports an in vivo-like situation (Dunn et al., 1989). With the cells in contact

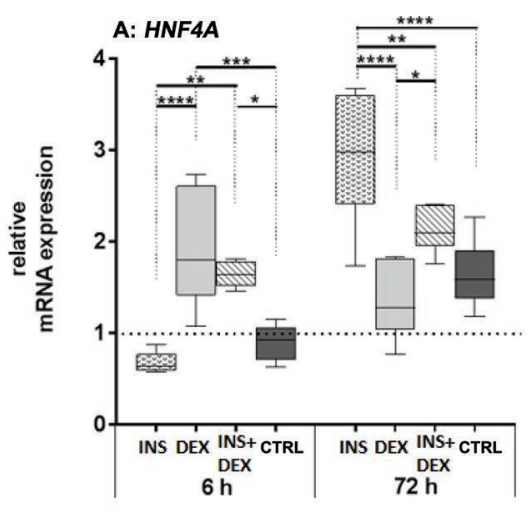

D: PCK1
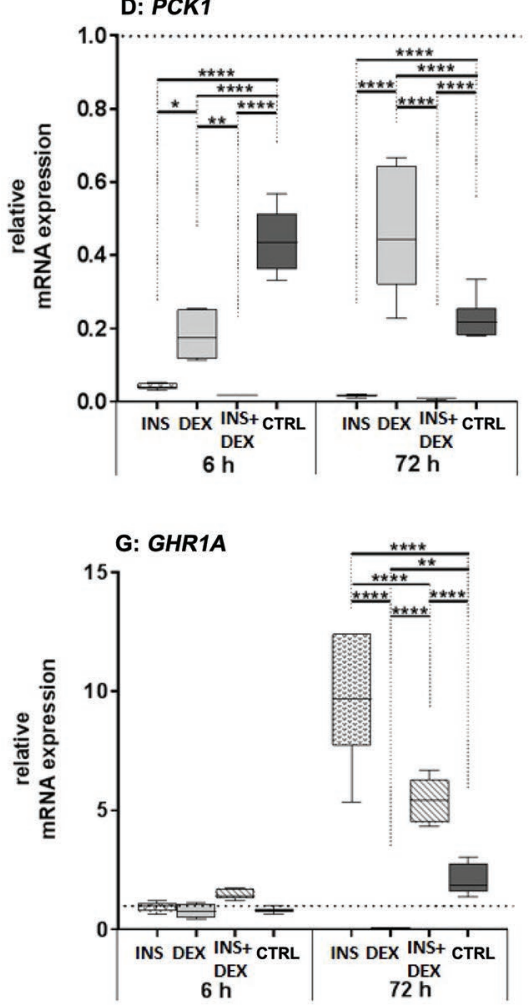
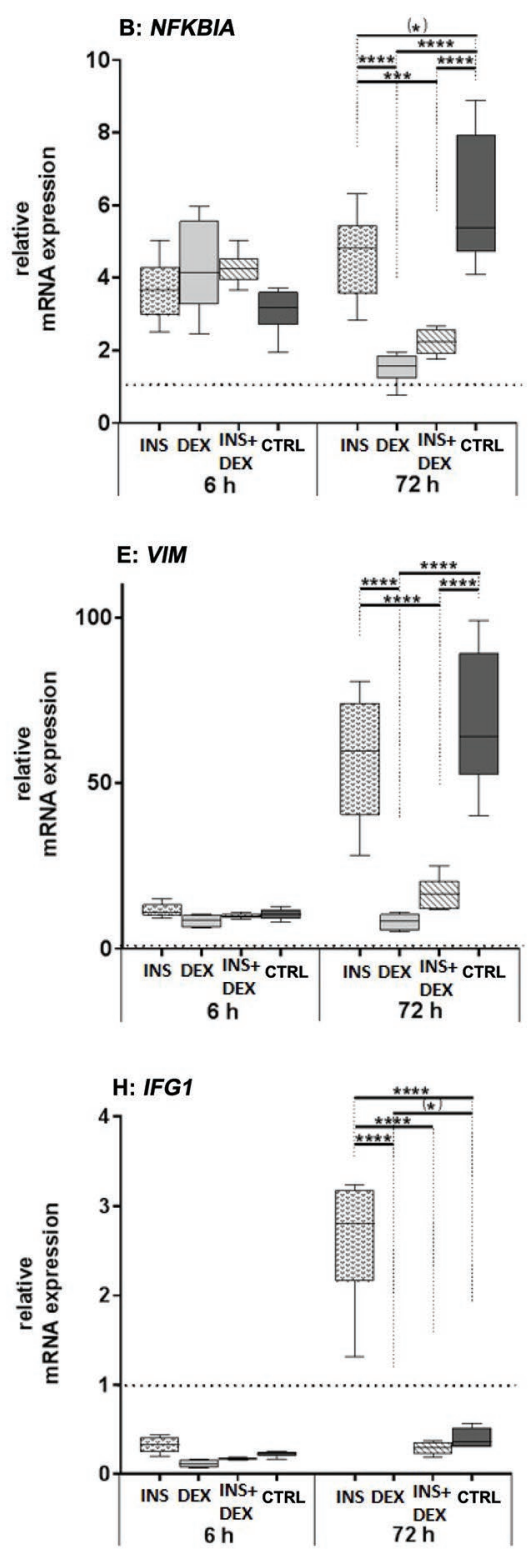
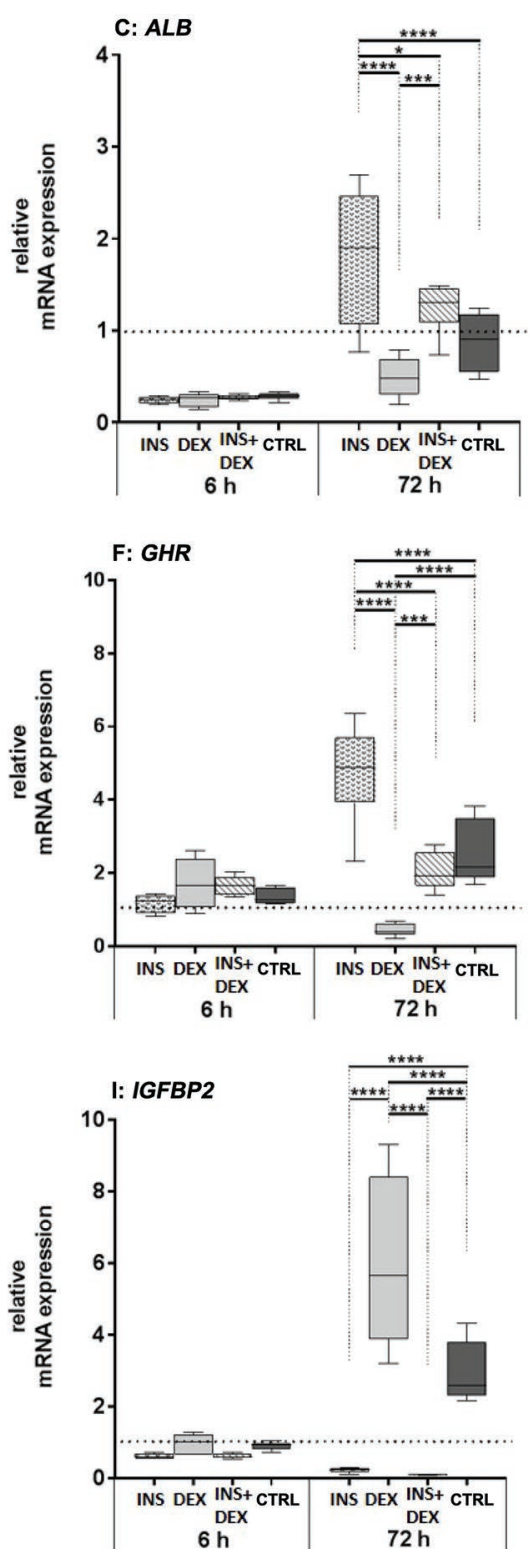

Figure 3. Relative mRNA expression of hepatocyte nuclear factor $4 \alpha(H N F 4 A)$, nuclear factor- $\kappa$ B-inhibitor $\alpha(N F K B I A)$, albumin $(A L B)$, cytosolic phosphoenolpyruvate carboxykinase (PCK1), vimentin (VIM), growth hormone receptor total (GHR), GHR1A, IGF1, and IGF binding protein-2 (IGFBP2) in adult primary bovine hepatocytes in a sandwich culture system between 2 layers of collagen after culturing 6 and $72 \mathrm{~h}$ Williams' Medium E supplemented with insulin (INS), dexamethasone (DEX), both (INS+DEX), or no hormone substitute (CTRL). The mRNA data are given as $\Delta \Delta \mathrm{Ct}(\mathrm{Ct}=$ cycle threshold) relative to a calibrator (cells were collected immediately after the purification step and directly frozen at $-80^{\circ} \mathrm{C}$ until analyses). Glyceraldehyde 3-phosphate dehydrogenase (GAPDH) was used as the reference gene. Values are given as medians with 25 and $95 \%$ quartiles. Error bars indicate minimum to maximum. Asterisks indicate significant differences at $(*) P<0.1,{ }^{*} P<$ $0.05, * * P<0.01,{ }^{* * *} P<0.001, * * * * P<0.0001$ 
with an extracellular matrix at 2 sides, repolarization of the cells is supported, which leads to an in-vivo-like morphology and polarization of the hepatocytes (Berthiaume et al., 1996). One aspect of the polarization is that the hepatocytes form bile canaliculi with their apical membranes (LeCluyse et al., 1994), as determined by brightened and refracting structures between cells under phase-contrast microscopy, which in the present study, were detected at d 4 . In future studies, the excretion potential of those bile canaliculi should be tested using fluorescence dyes. This repolarization of cells in a sandwich culture supports in vivo-like functions and prevents the hepatocytes from dedifferentiation. Both are crucial to support hepatocyte-like function (Talamini et al., 1997; Godoy et al., 2013; Zeigerer et al., 2017). As a marker of dedifferentiation in hepatocytes, the intermediary filament vimentin is widely used. The expression of vimentin is typical for mesenchymal but not for epithelial cells, so vimentin should be not expressed in hepatocytes (Godoy et al., 2009). In the present study, dexamethasone suppressed vimentin mRNA expression in adult primary bovine hepatocytes, and expression increased with the time of cultivation. These results confirm those of Godoy et al. (2010) with murine hepatocytes, in which dexamethasone also inhibited the expression of vimentin. In contrast, in the same study insulin showed the potential to increase the expression of vimentin, similar to the present study. Corresponding to this finding, the percentage of dead/ live cells was higher at d 4 with INS compared with DEX, INS+DEX, and CTRL.

To evaluate the hepatocyte-like function, we measured LDH activity and urea concentration in the media. Leakage of the cytoplasmic enzyme LDH can be used as an indirect marker of hepatocyte viability (Mitchell et al., 1980). The results of the present study indicated high LDH leakage at the beginning of the culture, decreasing continuously thereafter, which might indicate an increase in the rate of cell death immediately after cell separation and stabilization. It has to be noted that in the sandwich culture, no useful standardization with relation to cell count was possible. But the single wells were morphologically assessed each day to determine that the cell count was always comparable between wells, with one exception. At d 4 more dead cells were detected in INS cultivated cells compared with DEX, INS+DEX, and CTRL. Therefore, the lower urea production on d 4 might also have been because fewer cells were vital. Sidhu et al. (2004) indicated a suppressive effect of dexamethasone in the medium on $\mathrm{LDH}$ leakage in rat hepatocytes, which we could not confirm in the present study. On d 4 of the present study, we detected no effect of either INS or DEX. However, the highest urea production was found on $\mathrm{d}$
4 with INS+DEX, and even DEX alone had a stimulatory effect on urea production. In agreement with this Okun et al. (2015), also found an increased production of urea by dexamethasone, and Nebes and Morris (1988) found that dexamethasone has a direct effect on carbamoylphosphate synthetase I, argininosuccinate synthase, argininosuccinate lyase, and arginase 1, with increases in mRNA expression of urea in culture with dexamethasone.

The underlying reason for dexamethasone addition to the medium for hepatocyte culture is not only to depress possible dedifferentiation, but also for its anti-inflammatory potential, which was indicated in the present study by the suppression of $\mathrm{I} \kappa \mathrm{B} \alpha$ expression. We used I $\kappa \mathrm{B} \alpha$ to assess the inflammatory status of the hepatocytes, because it is an indirect measure of nuclear factor- $\kappa \mathrm{B}$ activation (Bottero et al., 2003; Paciolla et al., 2011). As well, HNF4a is used as a marker for hepatocyte-like differentiation (Panda et al., 2015; Gleich et al., 2016). In contrast to the present study, Onica et al. (2008) and Oyadomari et al. (2000) reported a stimulation of HNF $4 \alpha$ expression in human and rat hepatocytes, which might have been due to species differences.

To summarize, these data showed that dexamethasone prevented hepatocytes from dedifferentiation and apoptosis/inflammation, but we also detected hepatocyte-like functions in the production of albumin and the downregulation of PEPCK-C (PCK1) expression after insulin administration. Therefore, short-term cultivation without dexamethasone but with an alternative anti-inflammatory drug might be necessary, because we clearly demonstrated that the addition of dexamethasone distinctly downregulated expression of GHR1A and GHR. In contrast, the addition of insulin clearly increased expression of GHR, GHR1A, and IGF1 mRNA, consistent with in vivo studies in which insulin increases GHR1A and IGF1 expression (Butler et al., 2003; Rhoads et al., 2004). As well, the suppression of GHR after $5 \mathrm{~d}$ of dexamethasone application in cows (Maciel et al., 2001) was consistent with the in vitro results of the present study. In primary rat hepatocytes, a high dose of dexamethasone decreased the expression of GHR mRNA (Beauloye et al., 1999). In the present study, $100 \mathrm{n} M$ insulin was added to the medium, in contrast to Ehrhardt and Schmicke (2016), in which only $1.74 \mathrm{n} M$ insulin was added to the medium. Therefore, the low insulin and high dexamethasone concentrations in the cell culture medium were responsible for the low GHR expression in the previous study (Ehrhardt and Schmicke, 2016). However, with $100 \mathrm{n} M$ insulin, additional hepatocytes showed fibroblastic protrusions, and the key enzyme for gluconeogenesis, PEPCK-C, was strongly downregulated. In further studies, an optimal 
(and physiological) insulin concentration in the medium should be elucidated to support GHR expression with increased physiological insulin concentrations. Moreover, other anti-inflammatory agents should be chosen. Dexamethasone at $100 \mathrm{n} M$ is routinely added to hepatocyte medium (Godoy et al., 2013). We used this concentration in the present study and in that of Ehrhardt and Schmicke (2016), but we clearly showed that this dose suppressed GHR expression. Additional detection of protein levels by detecting GHR protein with Western blot analysis would further confirm our findings but was not performed in the present study. To further characterize the functional GHR-specific signal transduction pathway, analyses should be initiated in future studies.

We showed an increase in IGFBP2 mRNA expression with dexamethasone, but insulin blocked the increase. This strong inhibition of IGFBP2 by insulin is also shown in vivo in lactating dairy cows at $73 \%$ (McGuire et al., 1995). In primary rat hepatocytes, insulin also inhibited IGFBP2 expression (Böni-Schnetzler et al., 1990; Scharf et al., 1996). When $100 \mathrm{n} M$ insulin was added to the medium, comparable to the dose used in the present study, no IGFBP-2 was detected in the medium (Scharf et al., 1996).

Based on our findings, the influence of warm ischemia time should not be underestimated; a short time between slaughter and cooling of the liver tissue had a positive effect on cell count and cell viability. Distinct improvements to the original isolation protocol (Ehrhardt and Schmicke, 2016) led to a massive amplification in the amount of viable adult primary bovine hepatocytes. Cultivation without dexamethasone ensured a basal GHR expression. We also observed in vivo results by demonstrating the increased expression of GHR and decreased expression of IGFBP-2 with insulin. This finding also indicated that GHR expression is reactive, revealing primary bovine hepatocytes in sandwich culture as a potential in vitro model for further functional studies on GHR expression.

\section{ACKNOWLEDGMENTS}

We thank Christa Kühn (Institute for Genombiology, FBN, Dummerstorf, Germany) for providing livers with SWI from the Chron Mast Project and D. Dusinski (Westfleisch SCE mbH Minden-Lübbecke, Germany) for providing livers with LWI. Moreover, we thank Martina Baumgarten (Clinic for Cattle, Endocrinology Laboratory, University of Veterinary Medicine Hannover, Germany) for analyzing LDH and urea and the working group of Jan Hengstler (IFADO, Dortmund, Germany) and Regina Stöber (IFADO, Dortmund, Germany) for assisting us with collagen.

\section{REFERENCES}

Bakala, A., W. Karlik, and M. Wiechetek. 2003. Preparation of equine isolated hepatocytes. Toxicol. In Vitro 17:615-621. https://doi .org/10.1016/S0887-2333(03)00112-7.

Beauloye, V., J. M. Ketelslegers, B. Moreau, and J. P. Thissen. 1999. Dexamethasone inhibits both growth hormone (GH)-induction of insulin-like growth factor-I (IGF-I) mRNA and GH receptor (GHR) mRNA levels in rat primary cultured hepatocytes. Growth Horm. IGF Res. 9:205-211. https://doi.org/10.1054/ghir.1999 .0110 .

Bennett, P. A., A. Levy, D. F. Carmignac, I. C. Robinson, and S. L. Lightman. 1996. Differential regulation of the growth hormone receptor gene: Effects of dexamethasone and estradiol. Endocrinology 137:3891-3896. https://doi.org/10.1210/endo.137.9.8756562.

Berthiaume, F., P. V. Moghe, M. Toner, and M. L. Yarmush. 1996. Effect of extracellular matrix topology on cell structure, function, and physiological responsiveness: Hepatocytes cultured in a sandwich configuration. FASEB J. 10:1471-1484.

Bhogal, R. H., S. M. Curbishley, C. J. Weston, D. H. Adams, and S. C. Afford. 2010. Reactive oxygen species mediate human hepatocyte injury during hypoxia/reoxygenation. Liver Transpl. 16:13031313. https://doi.org/10.1002/lt.22157.

Böni-Schnetzler, M., C. Schmid, J. L. Mary, B. Zimmerli, P. J. Meier, J. Zapf, J. Schwander, and E. R. Froesch. 1990. Insulin regulates the expression of the insulin-like growth factor binding protein 2 mRNA in rat hepatocytes. Mol. Endocrinol. 4:1320-1326. https:// doi.org/10.1210/mend-4-9-1320.

Bottero, V.. V. Imbert, C. Frelin, J.-L. Formento, and J.-F. Peyron. 2003. Monitoring NF-kappa B transactivation potential via realtime PCR quantification of I kappa B-alpha gene expression. Mol. Diagn. 7:187-194.

Butler, S.T., A. L. Marr, S. H. Pelton, R. P. Radcliff, M. C. Lucy, and W. R. Butler. 2003. Insulin restores GH responsiveness during lactation-induced negative energy balance in dairy cattle: Effects on expression of IGF-I and GH receptor 1A. J. Endocrinol. 176:205-217.

Caldwell-Kenkel, J. C., R. T. Currin, Y. Tanaka, R. G. Thurman, and J. J. Lemasters. 1989. Reperfusion injury to endothelial cells following cold ischemic storage of rat livers. Hepatology 10:292-299.

Caldwell-Kenkel, J. C., R. T. Currin, Y. Tanaka, R. G. Thurman, and J. J. Lemasters. 1991. Kupffer cell activation and endothelial cell damage after storage of rat livers: Effects of reperfusion. Hepatology $13: 83-95$

Cummins, S. B., S. M. Waters, A. C. O. Evans, P. Lonergan, and S. T. Butler. 2012. Genetic merit for fertility traits in Holstein cows: III. Hepatic expression of somatotropic axis genes during pregnancy and lactation. J. Dairy Sci. 95:3711-3721. https://doi.org/ 10.3168/jds.2011-4977.

Dunn, J. C., M. L. Yarmush, H. G. Koebe, and R. G. Tompkins. 1989. Hepatocyte function and extracellular matrix geometry: Longterm culture in a sandwich configuration. FASEB J. 3:174-177.

Ehrhardt, S., and M. Schmicke. 2016. Isolation and cultivation of adult primary bovine hepatocytes from abattoir derived liver. EXCLI J. 15:858-866. https://doi.org/10.17179/excli2016-794.

Fisher, M., R. Eversole, L. Beuving, and H. Jaeschke. 1997. Sinusoidal endothelial cell and parenchymal cell injury during endotoxemia and hepatic ischemia-reperfusion: protection by the 21-aminosteroid tirilazad mesylate. Int. Hepatol. Commun. 6:121129. https://doi.org/10.1016/S0928-4346(96)00337-4.

Flores-Morales, A., C. J. Greenhalgh, G. Norstedt, and E. Rico-Bautista. 2006. Negative regulation of growth hormone receptor signaling. Mol. Endocrinol. 20:241-253. https://doi.org/10.1210/me .2005-0170.

Forsell, J. H., B. W. Jesse, and L. R. Shull. 1985. A technique for isolation of bovine hepatocytes. J. Anim. Sci. 60:1597-1609.

Gleich, A., B. Kaiser, J. Schumann, and H. Fuhrmann. 2016. Establishment and characterisation of a novel bovine SV40 large Tantigen-transduced foetal hepatocyte-derived cell line. In Vitro Cell. Dev. Biol. Anim. 52:662-672. https://doi.org/10.1007/s11626 -016-0018-0. 
Godoy, P., J. G. Hengstler, I. Ilkavets, C. Meyer, A. Bachmann, A. Müller, G. Tuschl, S. O. Mueller, and S. Dooley. 2009. Extracellular matrix modulates sensitivity of hepatocytes to fibroblastoid dedifferentiation and transforming growth factor beta-induced apoptosis. Hepatology 49:2031-2043. https://doi.org/10.1002/hep .22880 .

Godoy, P., N. J. Hewitt, U. Albrecht, M. E. Andersen, N. Ansari, S. Bhattacharya, J. G. Bode, J. Bolleyn, C. Borner, J. Böttger, A. Braeuning, R. A. Budinsky, B. Burkhardt, N. R. Cameron, G. Camussi, C.-S. Cho, Y.-J. Choi, J. Craig Rowlands, U. Dahmen, G. Damm, O. Dirsch, M. T. Donato, J. Dong, S. Dooley, D. Drasdo, R. Eakins, K. S. Ferreira, V. Fonsato, J. Fraczek, R. Gebhardt, A. Gibson, M. Glanemann, C. E. P. Goldring, M. J. Gómez-Lechón, G. M. M. Groothuis, L. Gustavsson, C. Guyot, D. Hallifax, S. Hammad, A. Hayward, D. Häussinger, C. Hellerbrand, P. Hewitt, S. Hoehme, H.-G. Holzhütter, J. B. Houston, J. Hrach, K. Ito, H. Jaeschke, V. Keitel, J. M. Kelm, B. Kevin Park, C. Kordes, G. A. Kullak-Ublick, E. L. LeCluyse, P. Lu, J. Luebke-Wheeler, A. Lutz, D. J. Maltman, M. Matz-Soja, P. McMullen, I. Merfort, S. Messner, C. Meyer, J. Mwinyi, D. J. Naisbitt, A. K. Nussler, P. Olinga, F. Pampaloni, J. Pi, L. Pluta, S. A. Przyborski, A. Ramachandran, V. Rogiers, C. Rowe, C. Schelcher, K. Schmich, M. Schwarz, B. Singh, E. H. K. Stelzer, B. Stieger, R. Stöber, Y. Sugiyama, C. Tetta, W. E. Thasler, T. Vanhaecke, M. Vinken, T. S. Weiss, A. Widera, C. G. Woods, J. J. Xu, K. M. Yarborough, and J. G. Hengstler. 2013. Recent advances in 2D and $3 \mathrm{D}$ in vitro systems using primary hepatocytes, alternative hepatocyte sources and non-parenchymal liver cells and their use in investigating mechanisms of hepatotoxicity, cell signaling and ADME. Arch. Toxicol. 87:1315-1530. https://doi.org/10.1007/s00204-013-1078-5.

Godoy, P., S. Lakkapamu, M. Schug, A. Bauer, J. D. Stewart, E. Bedawi, S. Hammad, J. Amin, R. Marchan, W. Schormann, L. Maccoux, I. von Recklinghausen, R. Reif, and J. G. Hengstler. 2010. Dexamethasone-dependent versus -independent markers of epithelial to mesenchymal transition in primary hepatocytes. Biol. Chem. 391. https://doi.org/10.1515/BC.2010.010.

Green, J. C., C. S. Okamura, S. E. Poock, and M. C. Lucy. 2010. Measurement of interferon-tau (IFN-tau) stimulated gene expression in blood leukocytes for pregnancy diagnosis within 18-20d after insemination in dairy cattle. Anim. Reprod. Sci. 121:24-33. https: //doi.org/10.1016/j.anireprosci.2010.05.010.

Halliwell, B. 2006. Reactive species and antioxidants. Redox biology is a fundamental theme of aerobic life. Plant Physiol. 141:312-322. https://doi.org/10.1104/pp.106.077073.

Hewitt, N. J., M. J. G. Lechón, J. B. Houston, D. Hallifax, H. S. Brown, P. Maurel, J. G. Kenna, L. Gustavsson, C. Lohmann, C. Skonberg, A. Guillouzo, G. Tuschl, A. P. Li, E. LeCluyse, G. M. M. Groothuis, and J. G. Hengstler. 2007. Primary hepatocytes: Current understanding of the regulation of metabolic enzymes and transporter proteins, and pharmaceutical practice for the use of hepatocytes in metabolism, enzyme induction, transporter, clearance, and hepatotoxicity studies. Drug Metab. Rev. 39:159-234. https://doi.org/10.1080/03602530601093489.

Hughes, R. D., R. R. Mitry, A. Dhawan, S. C. Lehec, R. Girlanda, M. Rela, N. D. Heaton, and P. Muiesan. 2006. Isolation of hepatocytes from livers from non-heart-beating donors for cell transplantation. Liver Transpl. 12:713-717. https://doi.org/10.1002/lt.20732.

Ikeda, T., K. Yanaga, K. Kishikawa, S. Kakizoe, M. Shimada, and K. Sugimachi. 1992. Ischemic injury in liver transplantation: Difference in injury sites between warm and cold ischemia in rats. Hepatology. 16:454-461. https://doi.org/S0270913992002246.

Johnson, P. R., S. A. White, and N. J. London. 1996. Collagenase and human islet isolation. Cell Transplant. 5:437-452. https://doi.org/ 10.1016/0963-6897(95)02050-0.

Kobayashi, Y., C. K. Boyd, C. J. Bracken, W. R. Lamberson, D. H Keisler, and M. C. Lucy. 1999. Reduced growth hormone receptor (GHR) messenger ribonucleic acid in liver of periparturient cattle is caused by a specific down-regulation of GHR 1A that is associated with decreased insulin-like growth factor I. Endocrinology 140:3947-3954.
LeCluyse, E. L., K. L. Audus, and J. H. Hochman. 1994. Formation of extensive canalicular networks by rat hepatocytes cultured in collagen-sandwich configuration. Am. J. Physiol. 266:C1764-C1774.

Lee, S. M. L., C. Schelcher, M. Demmel, M. Hauner, and W. E. Thasler. 2013. Isolation of human hepatocytes by a two-step collagenase perfusion procedure. J. Vis. Exp. 79:e50615. https://doi .org/10.3791/50615.

Leung, K. C., N. Doyle, M. Ballesteros, K. Sjogren, C. K. W. Watts, T. H. Low, G. M. Leong, R. J. M. Ross, and K. K. Y. Ho. 2003. Estrogen inhibits GH signaling by suppressing GH-induced JAK2 phosphorylation, an effect mediated by SOCS-2. Proc. Natl. Acad. Sci. USA 100:1016-1021. https://doi.org/10.1073/pnas.0337600100.

Lucy, M. C., H. Jiang, and Y. Kobayashi. 2001. Changes in the somatotrophic axis associated with the initiation of lactation. J. Dairy Sci. 84:E113-E119. https://doi.org/10.3168/jds.S0022 -0302(01)70205-6.

Maciel, S. M., C. S. Chamberlain, R. P. Wettemann, and L. J. Spicer. 2001. Dexamethasone influences endocrine and ovarian function in dairy cattle. J. Dairy Sci. 84:1998-2009. https://doi.org/10.3168/ jds.S0022-0302(01)74643-7.

McGuire, M. A., D. A. Dwyer, R. J. Harrell, and D. E. Bauman. 1995. Insulin regulates circulating insulin-like growth factors and some of their binding proteins in lactating cows. Am. J. Physiol. 269:E723E730. https://doi.org/10.1152/ajpendo.1995.269.4.E723.

Mitchell, D. B., K. S. Santone, and D. Acosta. 1980. Evaluation of cytotoxicity in cultured cells by enzyme leakage. J. Tissue Cult. Methods 6:113-116. https://doi.org/10.1007/BF02082861.

Nebes, V. L., and S. M. Morris. 1988. Regulation of messenger ribonucleic acid levels for five urea cycle enzymes in cultured rat hepatocytes. Requirements for cyclic adenosine monophosphate, glucocorticoids, and ongoing protein synthesis. Mol. Endocrinol. 2:444-451. https://doi.org/10.1210/mend-2-5-444.

Okun, J. G., S. Conway, K. V. Schmidt, J. Schumacher, X. Wang, R. de Guia, A. Zota, J. Klement, O. Seibert, A. Peters, A. Maida, S. Herzig, and A. J. Rose. 2015. Molecular regulation of urea cycle function by the liver glucocorticoid receptor. Mol. Metab. 4:732740. https://doi.org/10.1016/j.molmet.2015.07.006.

Onica, T., K. Nichols, M. Larin, L. Ng, A. Maslen, Z. Dvorak, J. Pascussi, M.-J. Vilarem, P. Maurel, and G. M. Kirby. 2008. Dexamethasone-mediated up-regulation of human CYP2A6 involves the glucocorticoid receptor and increased binding of hepatic nuclear factor 4 alpha to the proximal promoter. Mol. Pharmacol. 73:451-460. https://doi.org/10.1124/mol.107.039354.

Oyadomari, S., F. Matsuno, S. Chowdhury, T. Kimura, K. Iwase, E. Araki, M. Shichiri, M. Mori, and M. Takiguchi. 2000. The gene for hepatocyte nuclear factor (HNF)- $4 \alpha$ is activated by glucocorticoids and glucagon, and repressed by insulin in rat liver. FEBS Lett. 478:141-146. https://doi.org/10.1016/S0014-5793(00)01840 -8 .

Paciolla, M., R. Boni, F. Fusco, A. Pescatore, L. Poeta, M. V. Ursini, M. B. Lioi, and M. G. Miano. 2011. Nuclear factor-kappa-B-inhibitor alpha (NFKBIA) is a developmental marker of NF- B/p65 activation during in vitro oocyte maturation and early embryogenesis. Hum. Reprod. 26:1191-1201. https://doi.org/10.1093/ humrep/der040.

Panda, S., S. Bisht, D. Malakar, A. K. Mohanty, and J. K. Kaushik. 2015. In vitro culture of functionally active buffalo hepatocytes isolated by using a simplified manual perfusion method. PLoS One 10:e0118841. https://doi.org/10.1371/journal.pone.0118841.

Pfaffl, M. W. 2004. Quantification strategies in real-time PCR. Pages 87-112 in A-Z of Quantitative PCR. S. A. Bustin, ed. International University Line, La Jolla, CA.

Piechotta, M., L. Holzhausen, M. G. Araujo, M. Heppelmann, A. Sipka, C. Pfarrer, H. J. Schuberth, and H. Bollwein. 2014. Ante partal insulin-like growth factor concentrations indicating differences in the metabolic adaptive capacity in dairy cows. J. Vet. Sci. $15: 343-352$

Piechotta, M., K. Kedves, M. G. Araujo, A. Hoeflich, F. Metzger, M. Heppelmann, A. Muscher-Banse, C. Wrenzycki, C. Pfarrer, H. J. Schuberth, M. Hoedemaker, H. Bollwein, and M. Kaske. 2013. 
Hepatic mRNA expression of acid labile subunit and deiodinase 1 differs between cows selected for high versus low concentrations of insulin-like growth factor 1 in late pregnancy. J. Dairy Sci. 96:3737-3749. https://doi.org/10.3168/jds.2012-6341.

Rauen, U., and H. de Groot. 2002. Mammalian cell injury induced by hypothermia the emerging role for reactive oxygen species. Biol. Chem. 383:477-488. https://doi.org/10.1515/BC.2002.050.

Rhoads, R. P., J. W. Kim, B. J. Leury, L. H. Baumgard, N. Segoale, S. J. Frank, D. E. Bauman, and Y. R. Boisclair. 2004. Insulin increases the abundance of the growth hormone receptor in liver and adipose tissue of periparturient dairy cows. J. Nutr. 134:1020-1027.

Scharf, J., G. Ramadori, T. Braulke, and H. Hartmann. 1996. Synthesis of insulinlike growth factor binding proteins and of the acidlabile subunit in primary cultures of rat hepatocytes, of Kupffer cells, and in cocultures: regulation by insulin, insulinlike growth factor, and growth hormone. Hepatology 23:818-827. https://doi .org/10.1053/jhep.1996.v23.pm0008666337.

Sidhu, J. S., F. Liu, and C. J. Omiecinski. 2004. Phenobarbital responsiveness as a uniquely sensitive indicator of hepatocyte differentiation status: Requirement of dexamethasone and extracellular matrix in establishing the functional integrity of cultured primary rat hepatocytes. Exp. Cell Res. 292:252-264. https://doi.org/10 $.1016 /$ j.yexcr.2003.09.001.

Talamini, M. A., B. Kappus, and A. Hubbard. 1997. Repolarization of hepatocytes in culture. Hepatology 25:167-172. https://doi.org/10 $.1002 /$ hep.510250131.
Tchaparian, E. H., J. S. Houghton, C. Uyeda, M. P. Grillo, and L. Jin. 2011. Effect of culture time on the basal expression levels of drug transporters in sandwich-cultured primary rat hepatocytes. Drug Metab. Dispos. 39:2387-2394. https://doi.org/10.1124/dmd .111 .039545

Toyokuni, S. 1999. Reactive oxygen species-induced molecular damage and its application in pathology. Pathol. Int. 49:91-102. https:// doi.org/10.1046/j.1440-1827.1999.00829.x.

Tuschl, G., and S. O. Mueller. 2006. Effects of cell culture conditions on primary rat hepatocytes-cell morphology and differential gene expression. Toxicology 218:205-215. https://doi.org/10.1016/j.tox .2005.10.017.

Winkelman, L. A., M. C. Lucy, T. H. Elsasser, J. L. Pate, and C. K. Reynolds. 2008. Short communication: Suppressor of cytokine signaling-2 mRNA increases after parturition in the liver of dairy cows. J. Dairy Sci. 91:1080-1086. https://doi.org/10.3168/jds.2007 $-0433$.

Zeigerer, A., A. Wuttke, G. Marsico, S. Seifert, Y. Kalaidzidis, and M. Zerial. 2017. Functional properties of hepatocytes in vitro are correlated with cell polarity maintenance. Exp. Cell Res. 350:242-252. https://doi.org/10.1016/j.yexcr.2016.11.027.

Zuo, L., T. Zhou, B. K. Pannell, A. C. Ziegler, and T. M. Best. 2015. Biological and physiological role of reactive oxygen species - the good, the bad and the ugly. Acta Physiol. (Oxf.) 214:329-348. https://doi.org/10.1111/apha.12515. 